\title{
Crystal Structure of $(R)$-2-Phenoxypropionic acid-(S)-Valine
}

\author{
Isao FuJII, ${ }^{* \dagger}$ Tetsuro Watadani, ${ }^{* *}$ Shigeki Nunomura, ${ }^{* *}$ and Yukio TaKahaShI** \\ *Department of Biological Science and Technology, Tokai University, 317 Nishino, Numazu, \\ Shizuoka 410-0321, Japan \\ **Daito Chemical Co., Ltd., 2700 Suga, Hiratsuka, Kanagawa 254-0022, Japan
}

\begin{abstract}
The crystal structure of $(R)$-2-phenoxypropionic acid- $(S)$-valine has been determined. In the crystal packing, the hydrophobic and hydrophilic layers are well separated along the b-axis. The adjusted shallow pocket on the hydrophobic layers accommodates the bulky $i$-propyl group of $(S)$-valine. The amino and carboxy groups of $(S)$-valine are intermolecular hydrogen bonded to the carboxy groups of phenoxypropionic acid.
\end{abstract}

(Received January 11, 2005; Accepted February 7, 2005; Published on web March 31, 2005)

Through diastereomer-salt formation, the separation of a racemic compound into its optically pure enantiomers is very commonly applied in industry. Optically active 2phenoxypropionic acid (PPA) ${ }^{1}$ has been known to be a useful chiral resolution agent of amines, such as 2-methylpiperazine. ${ }^{2}$ We clarified the optical difference of the molecular-recognition mechanism between the $(R)$-PPA and $(S)$-alanine $[(S)$-ALA $]$ complex,$^{3}$ and the $(R)$-PPA and $(R)$-pipecolic acid $[(R)$-PIP] complex. ${ }^{4}$ The shallow pocket on the hydrophobic layers plays an important role for chiral separation. In this paper, we focus on the molecular-recognition mechanism of the title compound, (I), which consists of a bulky $i$-propyl group (Fig. 1).

$(R)$-PPA and racemic valine (VAL) in a molar ratio of $1: 2$ were dissolved in hot water. The solution was slowly cooled at room temperature, and some fine rod-shaped colorless-crystals were obtained after a few days in a vial. $(R)$-VAL was in solution and excluded from co-crystals. A size of $0.4 \times 0.2 \times$ $0.2 \mathrm{~mm}$ crystal was used in X-ray diffraction experiments. Crystal and experimental data are given in Table 1. The crystal structure of (I) was solved by direct methods, SIR $88,{ }^{5}$ expanded using DIRDIF94, ${ }^{6}$ and refined by full-matrix least-squares. The absolute configuration was not experimentally determined, but was chosen to correspond to that of (R)-PPA. Non-hydrogen atoms were refined anisotropically. All of the hydrogen atoms were located in a difference-Fourier map, refined isotropically, and finally fixed. The atomic parameters for the non-hydrogen atoms are listed in Table 2. All calculations were carried out with the program package teXsan. ${ }^{7}$

An ORTEP- $3^{8}$ stereo drawing of (I) together with the atomic numbering is shown in Fig. 2. Selected bond lengths, bond

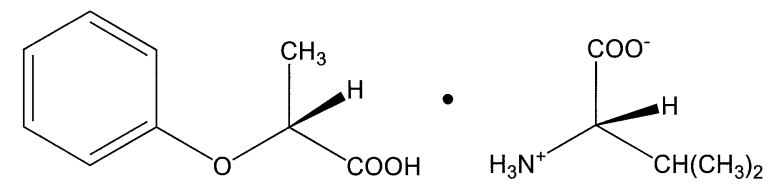

Fig. 1 Chemical structure of (I).

$\doteqdot$ To whom correspondence should be addressed.

E-mail: fujii@wing.ncc.u-tokai.ac.jp angles and torsion angles are given in Table 3. The crystal structure demonstrates the molecular recognition between $(R)$ PPA and $(S)$-VAL, shown in Fig. 2. The $(R)$-PPA molecule has an almost identical structure, as we already reported. The $(S)$ VAL molecule also displays a similar inner-salt structure, ${ }^{9}$ but the $i$-propyl group is rotated around the $\mathrm{C} 11-\mathrm{C} 12$ bond.

In the crystal packing, the hydrophobic and hydrophilic layers are well separated along the $b$-axis. The phenyl rings are packed in a herringbone-stacking mode. The carboxy group of PPA projects into the hydrophilic layer. The clearances of the carboxy groups of PPA on a hydrophobic layer make hydrophobic pockets. The shallow pocket surrounded by the four carboxy-groups of PPA accommodates the bulky $i$-propyl group of $(S)$-VAL. The crystal packing form is essentially similar to those of $(R)$-PPA- $(S)$-ALA and $(R)$-PPA- $(R)$-PIP.

The projected size of the shallow pocket is roughly estimated from the rectangular area that is made from the four chiral C8 atoms: $41.36(3), 38.39(3)$ and $41.36(3) \AA^{2}$ in the $(R)$-PPA- $(S)$ VAL, $(R)$-PPA- $(S)$-ALA and $(R)$-PPA- $(R)$-PIP, respectively. The lengths of sides of the rectangles are 7.649(2) and 5.407(2),

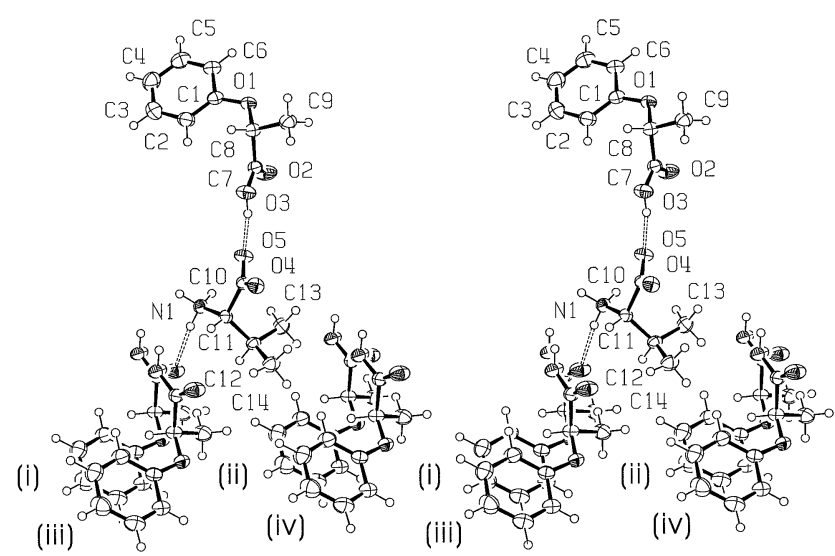

Fig. 2 ORTEP-3 stereo-drawing representing heavy atoms as 50\% probability ellipsoids and $\mathrm{H}$ atoms as circles of arbitrary size. The dashed lines show intermolecular hydrogen-bonds. Symmetry codes: (i) $x+1 / 2,1 / 2-y, 2-z$, (ii) $x-1 / 2,1 / 2-y, 2-z$, (iii) $x+1 / 2,1 / 2-$ $y, 1-z$, (iv) $x-1 / 2,1 / 2-y, 1-z$. 
Table 1 Crystal and experimental data

$$
\begin{aligned}
& \text { Formula: } \mathrm{C}_{9} \mathrm{H}_{10} \mathrm{O}_{3} \cdot \mathrm{C}_{5} \mathrm{H}_{11} \mathrm{NO}_{2} \\
& \text { Formula weight: } 283.32 \\
& \text { Crystal system: orthorhombic } \\
& \text { Space group: } P 2_{1} 2_{1} 2_{1} \quad Z=4 \\
& a=7.6493(4) \AA \\
& b=34.436(1) \AA \\
& c=5.4074(3) \AA \\
& V=1424.4(1) \AA^{3} \\
& D_{\mathrm{x}}=1.321 \mathrm{~g} / \mathrm{cm}^{3} \\
& \text { No. of reflections used }=1755 \\
& 2 \theta_{\max }=149.8^{\circ} \text { with } \mathrm{Cu} K_{\alpha} \\
& R=0.031 \\
& (\Delta / \sigma)_{\max }=0.003 \\
& (\Delta \rho)_{\max }=0.16 \mathrm{e} \AA^{-3} \\
& (\Delta \rho)_{\min }=-0.11 \text { e } \AA^{-3} \\
& \text { Measurement: Enraf-Nonius CAD4-Turbo } \\
& \text { Program system: Rigaku teXsan } \\
& \text { Structure determination: direct method (SIR88) } \\
& \text { Refinement: full-matrix least-squares }
\end{aligned}
$$

\begin{tabular}{|c|c|c|c|c|}
\hline \multicolumn{2}{|c|}{ Bond lengths $(\AA)$} & \multicolumn{3}{|c|}{ Bond lengths $(\AA)$} \\
\hline $\mathrm{O} 1-\mathrm{C} 1 \quad 1$ & $1.369(2)$ & O1 - C8 1. & \multicolumn{2}{|c|}{$1.422(2)$} \\
\hline $\mathrm{O} 2-\mathrm{C} 7$ & $1.205(2)$ & $\mathrm{O} 3-\mathrm{C} 7$ & \multicolumn{2}{|c|}{$1.302(2)$} \\
\hline $\mathrm{O} 4-\mathrm{C} 10$ & $1.249(2)$ & $\mathrm{O} 5-\mathrm{C} 10$ & \multicolumn{2}{|c|}{$1.259(2)$} \\
\hline N1 - C11 & $1.493(2)$ & C7 - C8 & \multicolumn{2}{|c|}{$1.531(2)$} \\
\hline C8 - C9 & $1.513(2)$ & $\mathrm{C} 10-\mathrm{C} 11$ & \multicolumn{2}{|c|}{$1.533(2)$} \\
\hline C11- C12 & $1.546(2)$ & C12- C13 & \multicolumn{2}{|c|}{$1.520(2)$} \\
\hline $\mathrm{C} 12-\mathrm{C} 14$ & $1.524(2)$ & & & \\
\hline Bond angles & $\left(^{\circ}\right)$ & Bond angles & \multicolumn{2}{|r|}{$\left({ }^{\circ}\right)$} \\
\hline $\mathrm{C} 1-\mathrm{O} 1$ - C8 & $118.4(1)$ & $\mathrm{O} 1$ - C1 - C2 & \multicolumn{2}{|c|}{$125.0(1)$} \\
\hline $\mathrm{O} 1-\mathrm{C} 1-\mathrm{C} 6$ & $115.3(1)$ & $\mathrm{O} 1-\mathrm{C} 8-\mathrm{C} 7$ & \multicolumn{2}{|c|}{$111.7(1)$} \\
\hline O1 - C8 - C9 & 106.7(1) & $\mathrm{O} 2-\mathrm{C} 7-\mathrm{O} 3$ & \multicolumn{2}{|c|}{$124.8(1)$} \\
\hline $\mathrm{O} 2-\mathrm{C} 7-\mathrm{C} 8$ & $123.5(1)$ & $\mathrm{O} 3-\mathrm{C} 7-\mathrm{C} 8$ & \multicolumn{2}{|c|}{$111.6(1)$} \\
\hline $\mathrm{O} 4-\mathrm{C} 10-\mathrm{O} 5$ & $126.9(1)$ & O4 - C10- C11 & \multicolumn{2}{|c|}{$116.4(1)$} \\
\hline O5 - C10- C11 & $116.7(1)$ & N1 - C11- C10 & \multicolumn{2}{|c|}{$109.7(1)$} \\
\hline N1 - C11- C12 & $110.5(1)$ & C7 - C8 - C9 & \multicolumn{2}{|c|}{$108.9(1)$} \\
\hline C10- C11- C12 & $112.7(1)$ & C11- C12- C13 & \multicolumn{2}{|c|}{$113.2(1)$} \\
\hline $\mathrm{C} 11-\mathrm{C} 12-\mathrm{C} 14$ & $110.7(1)$ & C13-C12- C14 & 110. & $3(1)$ \\
\hline Torsion angles & $\left(^{\circ}\right)$ & Torsion angl & & $\left(^{\circ}\right)$ \\
\hline C2-C1-O1-C8 & $-11.8(2)$ & C6-C1-O1-C & & $169.0(1)$ \\
\hline C1-O1-C8-C7 & $81.1(2)$ & $\mathrm{C} 1-01-\mathrm{C} 8-\mathrm{Cs}$ & & $-160.0(1)$ \\
\hline $\mathrm{O} 1-\mathrm{C} 8-\mathrm{C} 7-\mathrm{O} 2$ & $26.8(2)$ & $\mathrm{O} 1-\mathrm{C} 8-\mathrm{C} 7-\mathrm{O}$ & & $-156.9(1)$ \\
\hline O4-C10-C11-N1 & $157.3(1)$ & O5-C10-C11 & N1 & $-24.0(2)$ \\
\hline O4-C10-C11-C12 & $-79.1(2)$ & O5-C10-C11 & $\mathrm{C} 12$ & $99.6(2)$ \\
\hline N1-C11-C12-C13 & $75.7(2)$ & N1-C11-C12 & C14 & $-159.8(1)$ \\
\hline $\mathrm{C} 10-\mathrm{C} 11-\mathrm{C} 12-\mathrm{C} 1$ & $-47.4(2)$ & $\mathrm{C} 10-\mathrm{C} 11-\mathrm{C} 1$ & $-\mathrm{C} 14$ & $77.0(2)$ \\
\hline
\end{tabular}

CCDC 265988 contains the supplementary crystallographic data for this paper. These data can be obtained free of charge from The Cambridge Crystallographic Data Centre via www.ccdc.cam.ac.uk/data_request/cif.

Table 2 Atomic coordinates and equivalent isotropic thermal parameters $\left(B_{\text {eq }}\right)$

\begin{tabular}{ccccc}
\hline Atom & $x$ & $y$ & $z$ & $B_{\text {eq }}$ \\
\hline O1 & $0.2570(1)$ & $0.43530(3)$ & $0.8266(3)$ & $2.95(2)$ \\
O2 & $0.1818(2)$ & $0.35725(3)$ & $0.9156(3)$ & $3.90(3)$ \\
O3 & $0.3240(2)$ & $0.34161(3)$ & $0.5713(3)$ & $3.28(2)$ \\
O4 & $0.3297(2)$ & $0.24397(3)$ & $0.3373(2)$ & $2.78(2)$ \\
O5 & $0.3384(2)$ & $0.27087(3)$ & $0.7150(2)$ & $3.00(2)$ \\
N1 & $0.5491(2)$ & $0.21601(3)$ & $0.8953(3)$ & $2.43(2)$ \\
C1 & $0.4056(2)$ & $0.44286(4)$ & $0.9592(3)$ & $2.65(3)$ \\
C2 & $0.5582(2)$ & $0.42126(5)$ & $0.9477(4)$ & $3.34(3)$ \\
C3 & $0.6999(3)$ & $0.43205(6)$ & $1.0928(4)$ & $3.98(4)$ \\
C4 & $0.6901(3)$ & $0.46348(6)$ & $1.2506(4)$ & $4.24(4)$ \\
C5 & $0.5365(3)$ & $0.48461(5)$ & $1.2624(4)$ & $3.86(4)$ \\
C6 & $0.3958(2)$ & $0.47474(5)$ & $1.1179(4)$ & $3.15(3)$ \\
C7 & $0.2547(2)$ & $0.36611(4)$ & $0.7263(3)$ & $2.38(3)$ \\
C8 & $0.2663(2)$ & $0.40787(4)$ & $0.6305(3)$ & $2.58(3)$ \\
C9 & $0.1115(2)$ & $0.41573(5)$ & $0.4636(4)$ & $3.30(3)$ \\
C10 & $0.3663(2)$ & $0.24397(4)$ & $0.5624(3)$ & $2.11(2)$ \\
C11 & $0.4502(2)$ & $0.20685(4)$ & $0.6645(3)$ & $2.07(2)$ \\
C12 & $0.3153(2)$ & $0.17427(4)$ & $0.7128(3)$ & $2.33(3)$ \\
C13 & $0.1550(2)$ & $0.18821(5)$ & $0.8529(3)$ & $3.10(3)$ \\
C14 & $0.2614(3)$ & $0.15490(5)$ & $0.4711(4)$ & $3.33(3)$ \\
\hline
\end{tabular}

$B_{\mathrm{eq}}=(4 / 3) \Sigma_{i} \Sigma_{j} \beta_{i j}\left(\boldsymbol{a}_{i} \cdot \boldsymbol{a}_{j}\right)$.

7.330(2) and 5.237(2), and 6.647(2) and 6.222(2) $\AA$, respectively. It is considered that the phenyl groups, which are rearranged due to accommodation of the hydrophobic group of guest molecule, affect and restrict the shallow pocket form.

In the hydrophilic layer, the amino group is hydrogen-bonding to the carbonyl group of $(R)$-PPA on the same side of the
Table 3 Selected bond lengths $(\AA)$, bond angles $\left({ }^{\circ}\right)$ and torsion angles $\left({ }^{\circ}\right)$

hydrophobic layer $[\mathrm{N} 1-\mathrm{H} \cdots \mathrm{O} 2(x+1 / 2,1 / 2-y, 2-z)=$ $\left.2.905(2) \AA, \angle \mathrm{N} 1-\mathrm{H} \cdots \mathrm{O} 2=173(2)^{\circ}\right]$. The deprotonated carboxy group of $(S)$-VAL also undergoes hydrogen-bonding to the hydroxy group of $(R)$-PPA on the opposite side of the hydrophobic layer $[\mathrm{O} 3-\mathrm{H} \cdots \mathrm{O} 5=2.559(2) \AA, \angle \mathrm{O} 3-\mathrm{H} \cdots \mathrm{O} 5=$ $\left.168(2)^{\circ}\right]$.

\section{References}

1. H. O. Sorensen and S. Larsen, Acta Cryst., 2003, B59, 132.

2. H. Ikeda, T. Watadani, Y. Takahashi, and G. Hasegawa, Japan Patent, 2002, 332277.

3. Y. Takahashi and I. Fujii, Anal. Sci., 2004, 20, x77.

4. T. Watadani, Y. Takahashi, and I. Fujii, Anal. Sci., 2004, 20, x141.

5. SIR88, M. C. Burla, M. Camalli, G. Cascarano, C. Giacovazzo, G. Polidori, R. Spagna, and D. Viterbo, J. Appl. Cryst., 1989, 22, 389.

6. DIRDIF94, P. T. Beurskens, G. Admiraal, G. Beurskens, W. P. Bosman, R. de Gelder, R. Israel, and J. M. M. Smits, 1994, University of Nijmegen, The Netherlands.

7. teXsan, "Single Crystal Structure Analysis Software, Version 1.6", 1993, Molecular Structure Corporation, Texas, U.S.A.

8. ORTEP-3, L. J. Farrugia, J. Appl. Cryst., 1997, 30, 565.

9. B. Dalhous and C. H. Gorbitz, Acta Chem. Scand., 1996, 50,544 